\title{
Creating value in accounting education With a PUALITATIVE RESEARCH METHODOLOGY
}

\author{
Nadia Rhodes* \\ University of Johannesburg \\ nrhodes@uj.ac.za
}

Received: November 2014

Accepted: September 2015

\begin{abstract}
This article reports on the transformative design principles that were generated during the process of better aligning accounting education with accounting practice. Managing the risk of a disparity between accounting education and practice by matching the dynamics of the workplace and education arena could create value for the accounting graduate and the employer. In the process of change necessary for the integration of accounting software skills in accounting education transformation design principles were identified as imperative ground rules. The development and conceptualisation of the transformation design principles were drawn from iterative cycles, unique coding and analysis from the infusion of two research methods. The infusion of the two research methods contributed to the development of the transformative design principles, which led to the reform of accounting education in higher education. The transformative design principles developed are demonstrated to have generic properties that could be applied to other environments.
\end{abstract}

Keywords

Transformation design principles, accounting education, accounting practice, design-based research, information and communication technologies (ICT)

*Dr N Rhodes is a senior lecturer in the Department of Commercial Accounting, University of Johannesburg, South Africa. 


\section{INTRODUCTION}

Accounting education has not evolved to the extent required by industry itself. This lag created a gap in the knowledge and skills of accounting graduates as they move forward into a professional environment. The accounting industry and the job description of financial specialists have evolved to include a greater reliance on technology (Johnston \& Johnston, 1995; Wessels, 2007; Rhodes, 2012). However, in a study of the information and communication technologies (ICT) education offered to accounting students at South African universities in 2007, Wessels (2007) found that students had limited exposure to the use of accounting software packages. The identified gap led to an examination, undertaken by Rhodes (2012), to address the gap between accounting practice and accounting education in the higher education arena. Addressing the gap included the integration of information and communication technologies (ICT) into accounting education (Rhodes, 2012), thereby better aligning accounting education to the requirements of the workplace. The alignment of accounting education and accounting practice will bring the accounting graduate and the employer into alignment. This alignment should be possible if the use and understanding of accounting software packages were to be integrated into the entire learning experience for accounting diploma students - and this would need to happen throughout their studies. The integration throughout their studies could result in a more holistic learning experience matching the dynamics of the workplace.

The general aim was the development of an implementation plan for the integration of ICT into accounting education. The objective of this article is to highlight how the design logic of the research complemented the aim to add value with the elucidation of the design principles that emanated from the study. This article reports on a larger study paying particular attention to the findings from the process of curriculum change necessary for the integration of accounting knowledge and the application of the required skills in the world of work. Based on the curriculum reform process transformative design principles were identified that are imperative ground rules that should be considered in a process of curriculum change. These generic properties could be applied to other educational environments in the process of change.

The four distinct elements in the structure of the process followed to address the identified gap between the educational environment and the knowledge and skills required in accounting practice are discussed. The unique coding and analysis from the infusion of two research methods are highlighted. Finally, the transformative design principles are presented.

\section{DESIGN PROCESS}

This article reports on the curriculum development in a new three-year accounting diploma offered in an Accounting department of a university. During the implementation, it was imperative for the successful management of change that the buy-in of staff of the department and management be sustained throughout the process.

Design-based research (DBR) formed the basis of this qualitative enquiry and was framed by cultural-historical activity theory. Design-based research (DBR) characteristics had an essential supportive and validating role and seemed to offer the essential elements to implement a meaningful process of curriculum transformation and acted as a gateway to positioning ICT in accounting education. DBR also supported the notion of the methodological issue of 'goodness 
of fit' (Henning, Gravett \& van Rensburg 2005; Merriam 2009; Creswell 1994; Denzin \& Lincoln 2003).

Characteristics of DBR have been described by various researchers (Amiel \& Reeves, 2008; Bannan-Ritland, 2003; Barab \& Arici 2005; Barab \& Squire, 2004; Design Based Research Collective, 2003; Edelson, 2002; Hakkarainen, 2009; Kelly, 2003; Reeves, Herrington \& Oliver, 2005; Wang \& Hannafin, 2005). The nine essential components of DBR relevant to this study have been categorised and summarised and a discussion is given of their supportive, verification and validating roles in the process of closing the gap in accounting education and accounting practice, the integration model, the PSI and practical implementation.

Firstly, DBR facilitates the confluence of a series of approaches with the intention of effecting change, implemented through new theories, artefacts and practices to potentially impact learning and teaching in its naturalistic context. At the heart of this methodology are the design and the ecology of learning, with both the pragmatic and theoretical orientation being evident (Cobb et al., 2003). Also emphasised is the iterative, interventionist, innovative, design-based and theory-orientated characteristics. Specifically referred to is the pragmatic orientation, in which the theories developed "do real work in practical educational contexts" (Cobb et al., 2003:13). The PSI and the integration model are at the convergence of the cycles of refinement for the changes in the department of Commercial Accounting. These new designs for the integration of accounting education and ICT will potentially change the teaching and learning of accounting education to incorporate the skills needed in accounting practice. The designs considered both the practical and theoretical implications of teaching and learning to have the maximum potential to effect change. The iterative, interventionist, innovative, design-based and theory-orientated characteristics of DBR were needed to shape and model the designs.

Secondly, DBR involves real-life settings, in which most learning actually occurs. The PSI is designed to facilitate a learning experience for the lecturers teaching the diploma students within the $\mathrm{UJ}$ context. This real-life setting, coupled with a synergy of skills and experience, provides the greatest potential for learning.

Thirdly, DBR involves multiple dependent variables. In the three environments of accounting, education and ICT, the resulting multiple variables needed to be considered in a holistic and interactive stance in the design of the integration model and the PSI. This was imperative for a potential pragmatic implementation and integration across these three disciplines. I argue that the iterative cycles of DBR facilitated the consideration of these multiple variables.

Fourthly, DBR focuses on characterising the situation in all its complexity. In the design of the PSI it is necessary to include all practical considerations which characterise the situation in the Commercial Accounting department for the implementation to be effective. In the design of the integration model and the PSI, four iterative cycles were identified which enabled the consideration of these three disciplines to be aligned for a potential integration process to take place.

As regards the fifth characteristic, the DBR cycles involve flexible design revisions through rigorous and reflective inquiry to test and refine innovative learning environments. Of the four cycles that facilitate the refinement of the PSI and the integration model the first is the focus groups and the interviews together with all the literature and the examination of the accounting practice and ICT worlds that relate to this study. The second cycle is the refinement of the developments through the feedback forms from the staff buy-in workshop. The third cycle is the further refinement from the staff orientation PSI workshop and the final is the validation cycle, in 
which all these processes converge in the validation of the design of the PSI and the integration models.

Complex social interactions have been identified as the sixth characteristic in DBR, which I believe was a crucial component in the design of the study. It was imperative that in this change process the staff buy-in was always evident. The support of the management of UJ was necessary for the process to be implemented and the partnership with industry was a critical aspect in the process of the design of the PSI. The social interaction of the staff, management and industry is evident from the first to the final phase of these iterative cycles.

The seventh characteristic involves looking at multiple aspects of the design and developing a profile that characterises it in practice, thereby creating a bridge between universities and practitioners and increasing the potential impact and value of educational research. Although set in the naturalistic context of the Commercial Accounting department for the diploma students, it is not context-bound and I contend that the PSI and the integration model designs could be adopted and adapted in other accounting educational settings. The involvement of the staff of the department was an imperative design feature facilitated by the sixth characteristic of DBR.

The intensive collaboration among researchers and practitioners promulgated by the eighth characteristic is evident in the design of the PSI. It is an imperative that the teaching and learning experiences of the lecturers in the Commercial Accounting department was considered in the developmental phase, hence the focus groups, the staff buy-in workshop and the orientation workshop involved the staff of the Commercial Accounting department and practitioners from industry.

Lastly, the ninth characteristic involves a commitment to sharable theory construction and explanation while solving real-world problems. The theory is believed to have ecological validity, as it is set in real-world practice and the teaching and learning theories developed will serve the greater educational community while solving the real problem of a lack of integration and underskilled graduates. The element of complex social interactions, being the sixth component, was considered during the analysis of the data with the use of Engeström's activity theory as an analytical tool within the framework of Cultural Historical Activity Theory (CHAT).

These summarised characteristics are evidence that the possibilities of reform through the methodology of DBR are an important aspect in any study. The Design Based Research Collective (2003:8) iterates four prospects of DBR in education, as reproduced in italics below. The four areas in which DBR is seen as having the most promise in the reform of accounting education are as follows:

1. Exploring possibilities for novel learning and teaching environments. DBR has provided an opportunity to understand the real-world demand on the evolution needed in accounting education and that placed on the novel design of the PSI to increase the potential of successful implementation.

2. Developing contextualised theories of learning and teaching. DBR is argued to be of value in addressing research relating to the optimal design features of the PSI, which is aimed at being the enactment of the interventions to close the gap in accounting education and accounting practice.

3. Constructing cumulative design knowledge. DBR will lead to an understanding of relevant design knowledge set in the naturalistic context of the accounting education of the diploma 
students; that this knowledge is sharable will contribute to design knowledge theories and link these theories to applied understandings in other contexts for the advancement of accounting education.

4. Increasing human capacity for innovation. The design of the interventions and DBR has already provided opportunities for the exchange of expertise across disciplines. There will be opportunities for further innovation and new analytical techniques in the dynamic fields of education, technology and accounting practice.

CHAT has been identified as a road map for the alignment of an educational environment with the practical environment of practice, as well as demonstrating the potential to overcome challenges in educational theory and practice (Roth \& Lee 2007). The design of the intervention for the integration of accounting education and practice was framed by cultural-historical activity theory, as it was based in a complicated set of relationships between actions, tools, members, rules and a community (Engeström, 1999). The iterative cycles of design-based research and the infusion of the cultural-historical activity theory framework facilitated the development of the integration process to the extent that the programme was practical and feasible for implementation.

One of the focal features of DBR is the need to refine and inform the design through a cyclical and iterative process (Amiel \& Reeves, 2008; Bannan-Ritland, 2003; Barab \& Arici, 2005; Barab \& Squire, 2004; Design Based Research Collective, 2003; Edelson, 2002; Hakkarainen, 2009; Kelly, 2003; Reeves, Herrington \& Oliver 2005 and Wang \& Hannafin 2005). The iterative cycles of DBR facilitated the authentication and refinement of data as each cycle redefined and informed the next phase. The DBR basic iterative design that Reeves (2000) and Amiel and Reeves (2008) proposed as development research included four phases. An outline of the design phases and cycles are depicted in FIGURE 1 . Each cycle of feedback was filtered through the theoretical framework of CHAT. Each feedback cycle of refinement was analysed, coded and matched to Engeström's (1999:1) activity theory system.

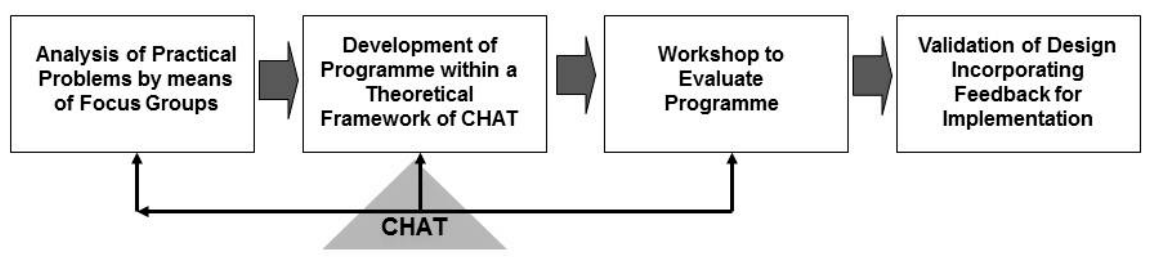

\section{Iterative cycles of refinement of problems, solutions, and methods}

\section{FIGURE 1: Outline of design phases and cycles}

Source: Adapted from Reeves (2000:9)

The four main phases provided a directional map from problem identification to verification and documentation of the interventions and integration model. The phases were sequential and each phase was linked together with a cycle of informing the next phase, as well as itself being refined and validated as the study progressed. 
The four phases included the analysis of relevant issues by means of a focus group and interviews with lecturers facilitating ICT in the accounting department to analyse and inform initial design of integration programme - phase 1 . The focus groups and interview were recorded, transcribed and analysed. Phase 2 was the development of the programme within a theoretical framework of CHAT and consideration of a further activity system for integration of ICT and accounting education. Three workshops with colleagues, management and industry in the diploma programme to evaluate the programme constituted the third phase. Feedback forms from each workshop validated the design and incorporated feedback into the design of the programme to promote implementation of the programme through their collaboration and support which were the feedback cycles of refinement and authentication. Phase 4 was the implementation phase.

\section{SUBSTANTIATION PROCESS}

The data was analysed and interpreted around the aims and objectives of the study and the conceptual categories arose "through our interpretation of data rather than emanating from them" (Charmaz, 2008:206). The use of action codes together with line-by-line coding not only facilitated an in-depth analysis of the data but also assisted in gaining insight into the data as well as highlighting the interrelated processes (Greyling, 2007:80). An added benefit of the use of codes that imply action was the ease of categorisation in linking them to Engeström's (1999) activity system.

In the first review of the line-by-line analysis of the data the action codes were identified and categorised into the six interrelated processes identified in the activity system as conceptualised by Engeström (1999). This activity system was used as a thinking tool in the analysis and interpretation of the data. This recognises all the interlocking forces and relationships that are relevant and pertinent to ensure a complete and comprehensive analysis and interpretation of the data. It assisted in the organisation of the data and helped to approach the data analysis in a systematic and methodical manner. In the second review of the data the selective or core codes used were the four elements of this study, namely the draft transformative design principles for the gap verification and validation; the integration model; the PSI; and the draft transformative design principles for practical implementation.

The process followed in the analysis and interpretation of the data collected from the focus groups and interview in phase 1 is illustrated in FIGURE 2. The same process was followed in the analysis and interpretation of the feedback forms from the staff and management workshops in phase three. The action taken on the left hand side is linked to the analysis process on the right hand side.

Using CHAT as an analytical framework helped to ensure that no detail was overlooked and the relevance of the history and experience of the participants was recognised to ensure a comprehensive analysis. With line-by-line coding the action or doing verb was identified and categorised into the six interrelated dichotomies of Engeström's (1999) activity triangle. The activity triangle provided an objective and comprehensive avenue to ensure that all aspects of the discussions were categorised into the six dichotomies. All the interlocking forces and relationships that were relevant and pertinent to this study were acknowledged. Discussions pertaining to the lecturers were categorised under 'subject'. 


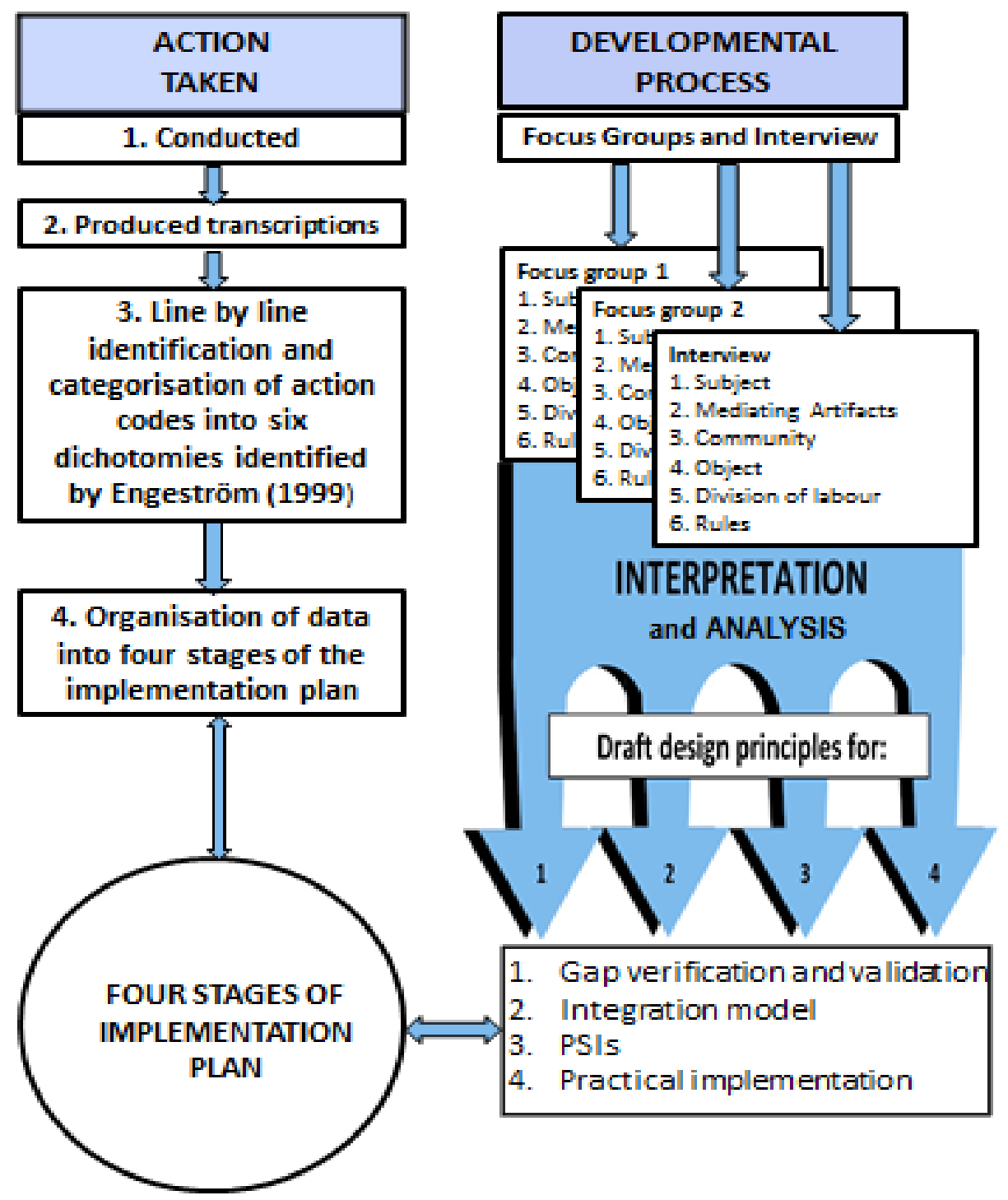

FIGURE 2: Data collection and analysis: substantiation cycle

Source: Author's design

The 'community' included accounting practitioners, accounting industry in general, graduates and students. Any discussions on faculty, academic, curriculum and assessment rules and regulations were categorised under the process 'rules'. The process 'division of labour' related to issues of management, such as the provision of the infrastructure for the implementation plan. 'Mediating artefacts' category was used for issues relating to the ICT tool, books, accounting software and other educational tools. The 'object' category was used for topics and issues relating to the process of integration. The action verbs were then linked to the six dichotomies in Engeström's (1999) activity triangle. In the second review of the data the selective codes used were the four stages of the implementation plan. The second review of the data was conducted 
from the first categorisation, in which each of the six dichotomies was further interpreted into the four stages of the implementation plan. The two reviews of the data provided a systematic and methodical approach for the interpretation of the data.

\section{PRINCIPLE IDENTIFICATION PROCESS}

\subsection{Four elements in the structure of the process}

This section focuses on the process followed to close the identified gap and the principles that developed from the reform of accounting education. There were four distinct elements in the structure of the process followed to address the identified gap between the education environment and the knowledge and skills required in accounting practice.

The essential elements were firstly that the staff and management involved in the curriculum change needed to recognise, buy-in and to support the process to close an identified gap. The recognition of the gap by staff members and management is critical in the implementation of curriculum change as the epistemologies and pedagogies of the lecturers must be adapted in order for the new integrated knowledge and skills of the staff to be transferred to the students. Secondly, technology must be integrated into the coursework if learning is to be active and functional, and staff development is a key ingredient in this integration (Reganick, 1994). The planned series of interventions fostered the staff buy-in as well as provided the staff training to implement the ICT integrated teaching and learning environment. Thirdly, an integration model was designed for the enrichment of the knowledge with the integration of skills and supported other relevant 'tried and tested' educational tools. Finally, the implementation of a new integrated curriculum for all three years of the diploma would then make it possible to prepare the accounting diploma graduates for the workplace, which would in turn create the potential for 'star' graduates, with integrated knowledge and skills. The transformative design principles clarified in the analysis and interpretation of the findings of each iterative cycle are identifiable for each of the four elements of the process. However, each element is part of a whole process and is an integral and necessary part of the whole of the implementation programme.

The findings from each of the four stages of the research design were filtered and interpreted to identify the principles and ideas that had the potential to be used as generic transformative design principles. These distilled design principles relate to the four elements evident in the process to close the identified gap. Their generic characteristics are highlighted and linked to these four elements.

\subsection{First element: Gap verification and validation}

In the search for solutions to the questions of what, why, how, where and when the identified gap in accounting education could be closed, concepts and principles emerged. The recognition of the transformative design principles can be linked to the development of strands or threads of knowledge that can be woven together to form a tapestry of a process for the management of change. It was demonstrated that these transformative design principles, when woven together, formed a process that was practical and feasible for implementation.

One of the transformative design principles for the gap verification and validation is the necessity to recognise that there is a gap in the expectations of the employer compared to the skills and knowledge of the Accounting diploma graduate. The staff members in the department, in which 
the curriculum change and integration of ICT was implemented, were unanimous in recognising that there was such a gap and that it was important that it be closed. Benefits in closing the gap include cost savings for the employer, with the elimination of the expense of further training or development of a new graduate employee as he or she would have the skills and knowledge required in the workplace. Another transformative design principle would be the recognition of an opportunity to close the gap. To 'seize the opportunity' could be the impetus for the change process to commence. The verification and validation of a gap, need or contradiction between two environments should be carried out first before a process of change is implemented. To aid in the process these transformative design principles could be used as questions:

- Is there a gap or need between the relevant environments?

- If yes, then what is the extent of the gap?

- If the gap is extensive, is there any value to be attained in closing the gap?

If the closing of the gap would be beneficial then the final step would be to find or create an opportunity to close the gap.

\subsection{Second Element: Integration model}

The integration of new skills into a tried and trusted knowledge base should enrich knowledge, but also requires time and effort to work. The time spent on the teaching and learning of these skills should reinforce the theory in the knowledge base, not weaken it, and the knowledge support structure must be upheld. The skills, for example, the ICT skills required in the workplace, will need to substantiate and strengthen the science and the structure of the existent knowledge foundation (Anderson \& Krathwohl, 2001). The accounting integration model is based on the rules and principles of accounting as taught in the textbooks. Accounting software and the integrated ICT skills do not contradict these. While lecturing and while new educational tools are in development, lecturers are necessarily adapting their pedagogy. It is necessary therefore to have the assurance of trusted teaching tools. An important transformative design principle is that the skills to be incorporated in an educational environment are relevant, authentic and real to life (Greyling, 2007). The skills that are integrated in accounting follow real-life scenarios and match the dynamics of the business cycles and are thus authentic and relevant. This is a crucial principle that must be evident for the staff, for the management and for industry to buy into a process of change. The skills will need to add value to the education of a graduate, thus ensuring he or she is better skilled and ready for the workplace. The integration model should empower students to translate their abstract knowledge into practical skills.

\subsection{Third element: Planned series of interventions}

The planned series of interventions were designed for the staff members of the department to maintain their buy-in to the process of change to align accounting education to accounting practice. This required a change in their epistemologies and pedagogies. The culture and history of the lecturers in the department was based on teaching accounting by means of the 'chalk and talk' method from a textbook. Three real fears in the minds of the staff become evident with the implementation of the interventions to integrate the accounting software into their classrooms.

The first fear was expressed as that of the unknown, as the staff members were uncomfortable with the idea of dealing with issues that might arise with a classroom of students and computers compared to being in control of the classroom in a way to which they had grown accustomed. 
Learning by doing for the staff was stressed as important for them to apply accounting software skills, and that the staff interventions be planned and implemented before the integration process commenced for the students. This would then allow the lecturers to prepare the lectures and learning material and facilitate the application of their new pedagogical knowledge. One of the final interventions was for the staff to train the selected tutors in the computer laboratories, and although not all issues arose they were more confident in the implementation of ICT in the classroom.

The second fear was that of a lack of support in this new teaching environment. Tutors were trained and provided to assist the staff in the practical periods on a ratio of approximately 1 to every 25 computers. The ICT staff members were also trained in the accounting software installation and support role. The third fear identified with the staff was that of making the jump from the acquisition of a skill to teaching it. In the final intervention the staff were not only assessed on the acquisition of the relevant accounting software skills but were also required to provide evidence of the application of the accounting software with the submission of a real-life assignment, similar to that which the students would be required to prepare as a portfolio of evidence.

Three milestones in the training PSI for the lecturers were developed to allay these concerns. The first of which was the successful passing of the five accounting software or the accounting ICT core module assessments over a 10 -week period. This extended exposure with smaller sections of the accounting software learning material promoted a deeper engagement, which was a key ingredient for effective integration of the accounting software in the classroom (Greyling, 2007). Another feature of the training was that it was divided into sections that would match the training of the students. The accounting software core material was divided into sections that would match the real-life development of a business entity. This was envisaged to commence with a sole proprietor doing business with cash transactions that would then expand into giving credit to customers and receiving credit from suppliers. The business entity was also foreseen to initially commence with the provision of a service and then develop into a trading and manufacturing entity.

The second milestone in the series of training interventions for the staff was for them to complete an assignment to provide evidence of their ability to apply their accounting knowledge and skills. They were required to set up their own pseudo-business within specified parameters, which was also in line with what was envisaged for the new accounting diploma students' portfolio of evidence.

The last milestone was for the staff to train the tutors who would provide support in the practical sessions and conduct the tutorial sessions. The three milestones provided evidence of the acquisition of the knowledge and skills of accounting software as a tool for the integration of accounting knowledge, the application of the skill and knowledge, and lastly experience in a new teaching environment of the computer laboratories. The staff needed these interventions to allay fears of a complete change in the teaching and learning environment. A staff member commented, 'It gives us a lot of pride in our work to produce students who will immediately be relevant in the work place and who have a practical skill which is necessary in this day and age since very few entities use manual book-keeping'.

The generic transformative design principles that become evident for the staff interventions were that the staff needed to commit and engage as a key ingredient for the change of epistemologies and pedagogies (Greyling, 2007). The promotion of active involvement and collaboration supports the design principle that there be a commitment to the process and recognition of the need to 
engage. The tools to achieve the transformation were the computers, the integration model, the PSI, the accounting software, software manuals and the accounting textbooks. It was important to keep the tasks directed at achieving this transformation goal and stress that the software was merely one of the tools and not the focus in the transformation of the epistemologies and pedagogies. The staff members supported this need and that it was necessary to, 'Provide students with more hands-on and real-life experiences. Try to bring the world into the classroom ...' and that lecturers needed to adopt their pedagogy to ICT, as ICT cannot be adapted: 'I think it is going to be a learning curve for us as well now changing our whole approach to lecturing.' The staff stressed that the lecturers needed to be trained first for them to be able to change their pedagogy: 'You teach the lecturers and the lecturers apply what they have been taught.' Teaching and learning and the integration of ICT in the interventions were to be kept as real-life as possible. This would broaden the staff perception from academics to business people and if the staff could be more exposed to real-life accounting and think like business people they would be better lecturers in the integration process.

\subsection{Fourth element: Implementation}

It is important to recognise the need for management and industry support in the process of implementation. It is also crucial that the tools to support the integration process are in place and that the change process is sustained with a careful and detailed planning process. These implementation design principles are all critical and need to be clarified and understood by the community involved in the implementation process. The community need the assurance that management support all the changes in the teaching and learning environments, which will ensure that the staff members remain motivated and keen to implement the changes. In order to maintain the staff buy-in to the process of aligning education to industry, it is important that they are aware that industry supports the changes and that they will add value to the graduates' work-readiness.

\subsection{Summary of key transformative design principles}

In summary, the key transformative design principles for curriculum change that could be woven together for a process that is practical and feasible for implementation are presented below and classified under the headings of the four elements.

First element: Transformative design principles for gap verification and validation. In this element it is important to recognise the gap and the extent of the gap. There needs to be value added in closing the gap and an ability to seize the opportunity to close the gap. The second element is the transformative design principles for the integration model and the essential features are to enrich knowledge with skills; support other tried and tested educational tools; maintain authenticity and relevance; ensure that the model is friendly, appealing, inviting, and accessible and that it empowers the user. Maintaining the acquired skills ('use it or lose it') and supporting the cognitive process as well as the knowledge developmental process are imperative. The third element is the transformative design principles for the planned series of interventions (PSI) and the key features are to encourage a commitment and engagement to the PSIs; promote active involvement and collaboration; direct the tasks to achieve the goals or to solve the problems; provide activities with real-life evidence; respect experience and integrate new knowledge and skills; recognise evidence of integrated learning; provide flexible design and provide a safe and supportive environment. Lastly, the fourth element is the transformative design principles for implementation and the key features of this element are to recognise the need for support by 
management and industry, and to recognise the need for careful planning of implementation cycles and the need for all the above support during implementation.

\section{CONCLUSION}

In response to the recognition of a gap in the knowledge and skills of accounting graduates in the higher education arena, the process of curriculum change necessary for the alignment of accounting education and accounting practice was elucidated. Pioneering use was made of the research strategies - design-based research (DBR) and cultural-historical activity theory (CHAT) - in accounting education, and these strategies facilitated the design of this study and complemented the aim of developing and implementing a process for the integration of ICT into accounting education. These research strategies contributed to finding solutions to the questions of what kind of gap existed between accounting education and accounting practice, why this gap existed, and how it could be closed in order to better equip an Accounting diploma graduate with the skills and knowledge required in the workplace. It was demonstrated that the iterative cycles of design-based research (DBR) with the infusion of cultural-historical activity theory (CHAT) could increase the potential impact on the reform of education. The process to close the recognised gap is argued to have been developed and sustained through the infusion of DBR and CHAT. The conceptualisation of the transformative design principles was drawn from the iterative cycles of findings and lessons learnt in the implementation of the process. The transformative design principles developed and distilled from the findings displayed generic properties that could be applied to other educational environments and in turn enhance a procedure of curriculum change and sustain a process for the management of change. The process of addressing the identified gap in accounting in higher education was implemented when the extent of the gap and the value in closing the gap were recognised. The alignment of accounting education and accounting practice could bring the accounting graduate and employer into alignment, thereby adding value to the graduates. The transformative design principles developed from this process of curriculum change have generic properties that could be used as guidelines and transformative design principles for curriculum change and the management of the process of change in other educational environments.

\section{LIST OF REFERENCES}

Amiel, T. \& Reeves, T.C. (2008). Design-based research and educational technology: Rethinking technology and the research agenda. Educational Technology \& Society, 11(4), pp.29-40.

Anderson, L.W. \& Krathwohl, D.R. (2001). A taxonomy for learning, teaching and assessing: A revision of Bloom's Taxonomy of educational objectives: Complete edition. New York: Longman.

Bannan-Ritland, B. (2003). The role of design in research: The integrative learning design framework. Educational Researcher, 32(1), pp. 21-24.

Barab, S. \& Arici, A.J. (2005). Eat your vegetables and do your homework: A design-based investigation of enjoyment and meaning in learning. Educational Technology, pp. 15-21.

Barab, S. \& Squire, K. (2004). Design-based research: Putting a stake in the Ground. The Journal of Learning Sciences, 13(1), pp. 1-14.

Creswell, J.W. 1994. Research design. Qualitative and quantitative approaches. Thousand Oaks: Sage Publications. 
Charmaz, K. (2008). Grounded theory in the 21st century: Applications for advancing social justice studies. In N.K. Denzin \& Y.S. Lincoln (Eds.), Strategies of qualitative inquiry. Thousand Oaks: Sage Publications.

Denzin, N. K. \& Lincoln, Y.S. (2003). The landscape of qualitative research: Theories and issues, $2^{\text {nd }}$ edition. Thousand Oaks: Sage Publications, Inc.

Design Based Research Collective. (2003). Design-based research: An emerging paradigm for educational inquiry. Educational Researcher, 32(1), pp. 5-8.

Edelson, D.C. (2002). Design research: What we learn when we engage in design. The Journal of the Learning Sciences, 11 (1), pp. 105-121.

Engeström, Y. (1999). Activity theory and individual and social transformation. In Y. Engeström, R. Miettinen and R. Punamäki (eds.) Perspectives on activity theory. Cambridge: Cambridge University Press, pp. 19-38.

Greyling, F.C. (2007). The why and how of technology-assisted learning: authentic professional development for higher education practitioners. Doctoral Dissertation. Johannesburg: University of Johannesburg.

Hakkarainen, P. (2009). Designing and implementing a PBL course on educational digital video production: Lessons learned from design-based research. Education Technology Research Development, 57, pp. 211-228.

Henning, દ., Gravett, S. \& van Rensburg, W. (2005). Finding your way in qualitative research. Pretoria: Van Schaik Publishers.

Johnson, L.M. \& Johnson, V.E. (1995). Help wanted -- Accountant: What the Classifieds say about employers' expectations. Journal of Education for Business, 70(3), pp. 130-134.

Kelly, A.E. (2003). Theme issue: The role of design in educational research. Educational Researcher, 32(1), pp. 3-4.

Merriam, S.B. (2009). Qualitative Research. A guide to design and implementation. San Francisco: Jossey-Bass.

Reeves, T.C. (2000). Enhancing the worth of instructional technology research through 'design experiments' and other development research strategies. Symposium on international perspectives on instructional technology research for the $21^{\text {st }}$ century. New Orleans, LA, USA.

Reeves, T.C., Herrington, J. \& Oliver, R. (2005). Design research: A socially responsible approach to instructional technology research in higher education. Journal of Computing in Higher Education, 16(2), pp. 97-116.

Reganick, K.A. (1994). Using computers to initiate active learning for students with severe behavior problems. TH EJournal (Technological Horizons in Education), $72(3)$.

Rhodes, N. (2012). Transforming accounting education: Closing the gap between technology, education and accounting in higher education institutions. PhD. thesis. University of Johannesburg.

Roth, W. M. \& Lee, Y. L. (2007). 'Vygotsky's neglected legacy': Cultural-historical activity theory. Review of Educational Research, 77(2), pp. 186-232.

Wang, F. \& Hannafin, M.J. (2005). Design-based research and technology-enhanced learning environments. Educational Technology Research and Development, 53(4), pp. 5-23. 
Wessels, P.L. (2007). An analysis of the current IT education offered to accounting students at South African universities. South African Journal of Accounting Research, 21(1), pp. 103-126. 